\title{
Translation as Deconstruction: Infidelity in the Translation Process
}

\author{
Dominador L. Pagliawan \\ Leyte Normal University, Philippines
}

Received: 25-02-2017

Accepted: 02-04-2017

Published: $30-04-2017$

doi:10.7575/aiac.ijclts.v.5n.2p.19

URL: http://dx.doi.org/10.7575/aiac.ijclts.v.5n.2p.19

\begin{abstract}
Over the years, translation practice has constantly faced numerous challenges and demands. Among these is the necessity for the translator to stay faithful to the source text in transporting meanings to the target language. In actual practice, though, fidelity in translation proves rather remote, even close to impossible. Try as they do, translators fail to achieve precision in their translation tasks. Yet the translation practice remains needful and relevant. Viewing this seeming failure from the deconstructive critical lens in an attempt to salvage translation, this paper theorized and found out that the latter is rightly a form of deconstruction rather than a product of infidelity. This shows in various translation procedures which, when subjected to closer scrutiny, eventually manifest their deconstructive nature. This study, then, contributes insights into the increasing corpus of theories that govern the translation process.
\end{abstract}

Keywords: Translation, Deconstruction, Infidelity, Inevitability

\section{Introduction}

Through the years, translators had been pursuing accuracy in making various texts available in other languages. To them, creating the exact equivalent of a text in another language is a great challenge, the ultimate objective, in fact, that they should attain.

Such preoccupation holds true until today. Some modern-day translators may have tried new techniques, but to most of them, craving for precision prevails. The widely-preferred translation is still that which remains faithful to the original text. Various translation procedures are to make it possible. Occasionally, however, questions confront the latter, calling attention to their limitations, inconsistencies, and failures. When early translators, for instance, settled for the literal translation, they found out that some problems affecting accuracy surfaced. They had pinned their hopes on a procedure that proved rather unreliable.

Alternative ways thus came to mind for inclusion in the increasing number of translation practices. But even with the former's advent, or their merger with the rest, or with the development and adoption of other techniques, faithfulness to the original text remained elusive, somehow frustrating translators in their endless attempts. No matter how easily translatable a text is, certain nuances in the output, or their absence, just seemingly drag the latter farther away from the original text.

Besides experience and observation, studies attest that a translated work may just come close to the source text but could not, for some reasons, juxtapose it with an identical output, rendering translation according to Beckson and Ganz (1990: 289) as a mere "likeness of the original." This problem must have been aggravated by the high standard ideal translation demands. As the target languages and the messages communicated by the source texts would have it, translators fail to perfect their works. Still, no one makes an accurate translator, and no translation proves faithful enough to the original text.

While they may feel guilty about it, translators may find comfort in the idea that they are committing no offense at all. They are, in fact, into a breakthrough in the area of writing in general, and in artistic creation in particular. For though it is after perfection and faithfulness to the source text, translation works, consciously or otherwise, as a critical and creative device - as a form of deconstruction. This is what this paper is trying to prove, prompted by the prevalence of unfaithfulness in the translation practice.

\section{Problem on Infidelity}

Translation maybe partly described as the interpretation of a text's meaning, and the subsequent production of its equivalent text expressing the same message in a different language. Here, meaning in the source text is carried across to the target text. In this transfer of meaning, problems had been observed to surface, unfortunately threatening to impair accuracy.

Various factors cause such problems, foremost of which is the presence of idioms in languages which, according to Newmark (1988), have meanings that are hard to match with equivalent ideas. Baker (2011) cited two challenges that idiomatic expressions pose to translation: identifying and then translating idioms appropriately, and translating multiple aspects of meaning that idioms, or fixed expressions, carry to the target language. Deciphering idioms accurately, according to Mollanazar (2004), is a pitfall on the part of translators. The lack of an idiom's equivalent in the target language just prevails as a glaring problem (Lopez Rodriguez, 2009). Catford (1965) thus contended that meanings of 
idiomatic expression are not distinguishable with aggregate meanings of their constituents. Hence, attempts at producing respectable idiomatic translations would find the figures of speech as a constant challenge (Larson, 1984).

Other factors that cause problems to the translator are the differences between the source and target languages, the social contexts, and the cultures represented by both languages. Note, for instance, that languages may differ in concepts, articulation, organization, and categories. Culler (1976:21) identified it as "the disparity among languages." The wider the gap between two languages, the harder it is to transfer meanings between them. Structural and lexical differences between languages and multiword units like idioms and collocations, moreover, could cause ambiguity.

In a word-for-word correspondence between two languages, aspects like context, grammar rules, writing conventions, and idioms, are difficult to take into account, hence the notion that translation is a straightforward, mechanical process. When done by bilingual individuals with limited proficiency in one or both languages, translation risks itself of spillingover idioms and usages from the source text to the target text.

Small words whose meanings rely on context are likewise hard to translate. In fact, some of them are untranslatable especially when the translator wishes to maintain a similar grammatical category. Conveying the same meaning in the other language, like translating poems and songs requiring words that rhyme, also causes difficulty. Shortage of vocabulary in the target language likewise bocks the way. And if the translators are faced with complex grammar structures in the source text, it may ruin their chances of generating meanings in the target text.

It could be noted that in translation, there is no such thing as one-to-one correlations between words and phrases of different languages. Texts are not identically reproducible and equivalents between two languages do not exist. Just because one can speak a second language doesn't mean he makes a good translator. In fact, as common knowledge has it, one should translate only into his native tongue, not to a second language since total fluency in it is remote. He should have full grasp of the source language, should write well in the target language, and be well versed on the subject matter of the text.

Jakobson (1959: 233) claimed that “...translation involves two equivalent messages in two different codes. Equivalence in difference is the cardinal problem of language and the pivotal concern of linguistics." Jakobson perceived equivalence as, yes, logical equivalence: translation then comes to mean, changing an equivalent content from a code to another one. Thus, translation takes place at the sociolinguistic level, filling out a "deficit." One grapples with such a deficit; now, we can tell the result.

Since translation is a mental task, personal problems like a painful ailment, a legal battle, or a huge financial crisis, may affect the process. The translator must then be completely objective in handling the message as it is easy for misconceptions about the nature of language, the translation's ultimate purpose, and the translation work to creep in. Problems like these could threaten translation procedures and ultimately ruin the effectiveness of the translator's work. Other problems may include the translator's unfamiliarity with the subject matter, with the receptor language, with the nature of communication, and with the procedures he should use.

Apparently, a translator can never understand a foreign culture the same way the native person can. Thus, no matter how much he reads about life in a remote farm, he will never be able to experience rising at nights to the sounds of crickets, feeding the chickens by hand, or feeling the close intimate friendships (or enmities) with the villagers. These are beyond the experience of a twentieth-century urban dweller and can never be recaptured for him. They can only be understood intellectually, not with one's feelings.

Interestingly, the meaning of a word is not what its etymology suggests, but rather what the speech community understands it to be. Etymology is, of course, a fascinating field for linguists and non-linguists alike, and it contributes greatly to the understanding of the historical development of culture. But it contributes very little to the current understanding of a linguistic sign. A very troublesome area in translation, allusion seems to abound with culturespecific portions of a source language. Allusions carry a specific bulk in the original language and should be explicated in translation for them to yield the richness of the SL text, to the benefit of the target language audience. Appearing abundantly in literary translations (Albakry, 2004), allusions form part of prior cultural knowledge which the author takes for granted.

\section{Sources of Infidelity}

After citing numerous reasons that explain translation's unavoidable failure to stay faithful to the original texts, we may now take a look at specific problems embedded in the different translation procedures themselves. We will notice that, within these established procedures enumerated by Newmark (1988:81), certain problems that threaten translation accuracy exist.

\subsection{Literal translation}

Here, the grammatical constructions of the source text are converted to their nearest target text equivalents, but the lexical words are translated singly, despite being out of context. This is quite problematic. Figurative expressions, idioms, expressions, sayings, etc., cannot be translated literally since doing so would change their original meaning. Moreover, this type of translation ignores contexts, which should be taken into account in inferring meanings.

\subsection{Word-for-word translation}

This is the process in which the word order in the sentences of the source text is preserved and then translated singly based on their most common meanings. But not all languages follow the same sentence patterns. In English, for 
instance, the basic sentence pattern is subject-verb-object (S-V-O), as in I eat chicken. But in Philippine languages, this order doesn't apply since they follow the V-S-O pattern. This kind of translation therefore cannot be relied upon, more so that sometimes, it operates out of context, especially in proverbs and idioms.

\subsection{Adaptation}

This is said to be the freest form of translation used mainly for plays, particularly comedies, and poetry. The elements of the play such as theme, characters, and plot are usually preserved. The source language culture is converted into the target language culture and the text is rewritten. This conversion requires change, thus espousing infidelity, or unfaithfulness, to the original text. The rewriting invites risks since a culture in the source language may not be acceptable in the target language. Where is translation fidelity here?

\subsection{Communicative translation}

This is an attempt to render the exact contextual meaning of the original in such a way that both content and language are readily acceptable and comprehensible to the readership. The intention is good, trying to duplicate everything that the source text communicates. But it ignores social context, just preoccupied with that of the source text. What if it's a joke that is humorous to the source language users but is offensive to the target language readers? Surely, a translation of such case would be deemed imperfect, or inappropriate, by the target language audience.

\subsection{Free translation}

By its name alone, this translation process implies deliberate deviation from the source text. It accordingly produces the target language text without considering the style, form, and content of the original, almost coming up with another work albeit similar in some ways with the source text. Apparently, no attempt at faithfulness to the original work is done as it is a fully liberated process.

\subsection{Semantic translation}

It differs from 'faithful translation' for its resolve to take more into account the aesthetic value of the source text. In short, it tries to be faithful to the source text but pays more attention to what is artistic and beautiful; it has a particular focus. But, like any other translation process, it too cannot avoid the basic problems in translation. There is nothing special in it that could spare it from the onslaught of translation drawbacks.

\subsection{Idiomatic translation}

This one tries to reproduce the 'message' of the original text. However, it tends to distort nuances of meaning by preferring colloquialisms and idioms that do not exist in the original text. This is a resort to addition, opposite of omission, which are both dangerously poised to doing injustice to the original text. To import something that doesn't exist in the target language is a glaring departure from what is true and real.

\subsection{Faithful translation}

This one attempts to reproduce the exact, contextual meaning of the original text. But surrounded by constraints in grammatical structures of the target text, it is basically just an attempt. Its name doesn't necessarily suggest the translation is faithful. It's just more of a name rather than a description of result. It's just like any other translation type that is confronted by the problems already cited above.

Whatever translation procedure is opted, it is always for sure that, by the mere act of touching the source text, changes resulting in unfaithfulness to the original text would occur. The translation result would always be "more" or "less," both of which are suggestive of infidelity. Any translation can be "more, or less semantic-more, or less, communicative - even a particular section or sentence can be treated more communicatively or less semantically."

\section{Infidelity in Translation}

A well-known Italian saying has this to say: "traduttore, traditore" which means "translator, traitor," an observation that the translator is helplessly incapable of remaining faithful to the original text. This is explained, as Swiss linguist Ferdinand de Saussure put it, by the absence of absolute equivalence between the signifier and the signified.

Obviously, translation does a so-called transcreation, which basically means recreating a text for the target audiencevery much resembling deconstruction in the latter's view that texts could be written in various ways. It is used to ensure identicalness between the target text and the source text in every aspect: the message conveyed, style of the work used, the images and emotions evoked, and the cultural background depicted. But while the aim for accuracy is there, translation job also takes liberty to "create."

To Derrida's mind, deconstruction is transformed into the problem of translation. Some of his key concepts are highly correlated with translation. He believed that a better translation demonstrates the operation of deconstruction, a more telling critique of the metaphysics. God confounded the language of Semitic people building the Tower of Babel, in a deconstructive way. "Babel" represents language diversity and the necessity and difficulty of translation that should then make way for deconstruction.

Indeed, many practical and theoretical problems of translation can be rethought in the light of deconstruction. If there is no one origin, no transcendent meaning and, thus, no stable text, then translation is no longer meaning transfer, or text reproduction. The desire for translatability and incorporating sharp critique of linguistic and communicative approaches to translation will then complicate. Derrida's (non)concepts such as différance, iterability and supplementarity, are all directly relevant to translation theory. 


\section{Why Translation as Deconstruction}

Jacques Derrida, whose ideas predominate within deconstruction, underscored that as a system of signs, language and particularly words just assume meaning due to the contrast that exists between these signs (Derrida, 1997). Consequently, meaning is "never present," but is rather deferred, consciously or otherwise, to other signs-a common occurrence in translation. He believed "there is a self-sufficient, non-deferred meaning as metaphysics of presence." This is understanding a concept against its opposite, like tall/short, present/absent, normal/abnormal (Derrida, 1981).

If the task of deconstruction is to endlessly pursue the complex unfolding of things within the text (Derrida, 1981); if its aim is to locate and overturn oppositions within or among texts; if it holds the view that hierarchy of oppositions within a text is firmly established, then deconstruction must be justifying translation's rumored infidelity, and translation no doubt passes for a deconstructive act. As is commonly done in translation, deconstruction creates new terms necessary for analysis, to mark differences and interplay of concepts in opposition. So when translation comes up with new words, unfaithful though they are to the source text, it can readily find an ally and a backer in deconstruction.

Newmark (1988) asserts that the process of translation operates in four levels, namely: source text level, referential level, cohesive level, and level of naturalness. We may notice that in each of these levels, the process of deconstruction is surprisingly at work.

\subsection{Textual level}

At this level, the translator transposes the syntactic structures of the source text into corresponding structures in the target text. He changes these structures into something different in order to achieve target language naturalness.

This process of changing structures, based on the idea of deconstruction, is a deconstructive procedure, dismantling something to create a new and meaningful thing out of it.

\subsection{Referential level}

This is where the translator operates primarily with the message (or information) or semantics of the text. He decodes the meaning of the source text and builds the conceptual representation. He disambiguates polysemous words and phrases and decodes idioms and figurative expressions into the appropriate target language expression. There will be cases, while dealing with idioms and metaphors, when he will have to use literal expressions in the target language for having no corresponding equivalents. Such use of expressions not found in the original text is deconstruction in action, consistent with Derrida's idea that "there is no absolute equivalence between the signifier and the concept signified..." (Beckson and Ganz, 1990:57).

\subsection{Cohesive level}

This level links the textual and the referential levels, and deals with the structure/format of the text and information as well as with what Newmark (1988) calls the mood of the text. The translator investigates how various connectors link sentences, and structures the text and the underlying information structure. This is a deconstructive, formalist approach of focusing on the text which, according to Derrida, yields multiple ideas not covered by authorial meanings.

\subsection{Level of naturalness}

This level focuses exclusively on the construction of the target text, after having deconstructed the source text. Some things may just seem unnatural in the target language and complicate matters since naturalness is dictated by situations. Something may appear natural in one context but not in another. To ensure naturalness, one should read through his translation and spot unnaturally sounding parts, making them sound more natural. This, accordingly, is neglected by many translators.

Furthermore, in the different translation procedures that Newmark (1988b:82-91) had proposed, the process of deconstruction tends to manifest itself. Notice how translation fits into the idea of deconstruction in the following:

1.5 Naturalization: it adapts the SL word first to the normal pronunciation, then to the normal morphology of the TL. This is to deconstruct the opposition between speech and writing and open the way to the rest of this approach.

1.6 Functional equivalent: it requires the use of a culture-neutral word. In deconstruction, this is disassociation of words from any perceived reality.

1.7 Descriptive equivalent: in this procedure the meaning of the culture-based text is explained in several words, consistent with deconstruction's aim of constructing meanings.

1.8 Transference: it is the process of transferring an SL word to a TL text. It includes transliteration and is the same as what Harvey (2000:5) named "transcription." This, in deconstruction, is like cracking a nutshell open to disturb its secretive tranquility for other languages to perceive it.

1.9 Componential analysis: it means "comparing an SL word with a TL word which has a similar meaning but is not an obvious one-to-one equivalent, by demonstrating first their common and then their differing sense components." It seeks to deconstruct hidden meanings in structures, including words.

1.10 Cultural equivalent: it means replacing a cultural word in the SL with a TL one. However, "they are not accurate". In deconstruction, this is to create new concepts, not to synthesize the terms in opposition, but to mark their difference and eternal interplay. 
1.11 Synonymy: it is a "near TL equivalent." Here economy trumps accuracy. This could be explained by deconstruction's view that language is not a system of positive designations but a system of negative differentiations.

1.12 Shifts or transpositions: it involves a change in the grammar from SL to TL, for instance, (i) change from singular to plural, (ii) the change required when a specific SL structure does not exist in the TL, (iii) change of an SL verb to a TL word, change of an SL noun group to a TL noun and so forth. This is a deconstructive, formalist process focusing on the text as a self-contained linguistic entity.

1.13 Through-translation: it is the literal translation of common collocations, names of organizations and components of compounds. It can also be called: calque or loan translation. Deconstruction does such detailed verbal analysis to reveal the multiple meanings of key terms, even by examining their etymological roots.

1.14 Modulation: it occurs when the translator reproduces the message of the original text in the TL text in conformity with the current norms of the TL, since the SL and the TL may appear dissimilar in terms of perspective. This is suggested in deconstruction's indeterminacy and contrariness of language.

1.15 Compensation: it occurs when loss of meaning in one part of a sentence is compensated in another part. This means, in deconstruction, that all linguistic communication is characterized by radical uncertainty.

1.16 Paraphrase: in this procedure meaning is well explained. The explanation is much more detailed than that of descriptive equivalent inviting the reader, like deconstruction does, to enter into a free play of interpretation that never claims to achieve a final totalizing of meaning.

1.17 Recognized translation: it occurs when the translator "normally uses the official or the generally accepted translation of any institutional term," meantime when, according to Derrida, the imperfect signifying of language will defer the expression of full present meaning to some indefinite future.

1.18 Couplets: it occurs when the translator combines two different procedures just as deconstruction encourages critical inquiry and self-reflective thinking through various methodologies.

All of the above translation processes and procedures seemingly make provisions for deconstruction to be actively at work. Whatever they are, the latter could fit in with ease, as could be observed by anyone with sufficient knowledge about deconstruction, even without efforts at justifying its presence. It's only for purposes of satisfying a layman's grasp that explanations such as the above prove necessary. But in general, the argument that this paper tried to make about translation being one of deconstruction undoubtedly drove home its point.

\section{Conclusion}

Given the above findings, this paper concludes that, no matter how they try, translators fail to produce target texts that are perfectly identical with their source texts. Unfaithfulness to the original text is just utterly unavoidable since translation procedures, in whatever form, always change something that eventually results in infidelity. Certain problems contribute to and explain this seeming failure. Infidelity, though by all means avoided, eventually characterizes every translation effort. But translation practice, which remains to be enormously significant, need not end. All it takes is for people to properly make sense of it, not as a frustrated practice, but as a form of art, specifically as a mode of criticism and creative writing. Moreover, translators need not regret, nor feel guilty about it as they, after all, are artists themselves, working on translation but ending up doing deconstruction. Translation, then, is a form of deconstruction. The way translation works showcases deconstruction's principles and practice. In short, translation actually does a deconstruction in dealing with texts, both as a source text, and as a target text. Under the refuge of deconstruction, translation does not end up in banality. It may come short of its claims to accuracy, but it takes its rightful position as a form of art and a separate genre entitled to creative rights and artistic liberty.

\section{Acknowledgment}

The study was financed by Leyte Normal University.

\section{References}

Albakry, M. (2004). Linguistic and cultural issues in literary translation. [Online] Available: http://accurapid.com/journal/29liter.htm (November 17, 2006)

Beckson, K. and Ganz, A. (1990). Literary Terms, A Dictionary. (3rd Ed). London: Andre Deutsch Limited.

Catford, J. C. (1965). A Linguistic Theory of Translation: an Essay on Applied Linguistics. London: Oxford University Press.

Culler, J. (1976). Structuralist poetics: structuralism, linguistics, and the study of literature. Cornell: Cornell University Press.

Derrida, J. (1997). Chapter 1 The End of the Book and the Beginning of Writing. Of Grammatology. translated by Gayatri Chakravorty Spivak (Corrected ed.). Baltimore: The Johns Hopkins University Press.

Derrida, J. (1981). Positions. translated and annotated by Alan Bass (1st ed.). Chicago: The University of Chicago Press. 
Derrida, Jacques (1981). Interview with Jean-Louis Houdebine and Guy Scarpetta. Positions. translated and annotated by Alan Bass (1st ed.). Chicago: The University of Chicago Press.

Hervey, S and Higgins, I. (1992). Thinking Translation. London \& New York: Routledge.

Jakobson, R. (1959). On linguistic aspects of translation. Brower, R. On Translation. Harvard University Press.

Larson, M. L. (1984). Meaning-based translation: A guide to cross-language equivalence. University press of America López Rodríguez, C. L., José Antonio Prieto Velasco and Maribel Tercedor Sánchez (2009). "Sharing Environmental Information through Multilingual Terminological and Multimedia Resources: The Role of Accessibility in Increasing Public Awareness Towards Sustainable Growth.” Jiří Hřebíček Et Al. (Eds) . Towards Eenvironment. Opportunities of Seis and Sise: Integrating Environmental Knowledge in Europe. Prague: Masaryk University, (2009). Prague: Masaryk University.

Mollanazar, H. (2004). Translation Movement. Translation Studies Quarterly. 2(6).

Newmark, P. (1988a). A Textbook of Translation. New York, USA: Prentice Hall.

Newmark, P. (1988b). Approaches to Translation. New York: Prentice Hall International. 